\title{
Behavioral and Emotional Problems Among Jordanian and Syrian Refugee Children in Noncamp Settings
}

\author{
Bayan Sarsour ${ }^{1}$, MD; Ashraf Aqel Sr ${ }^{1}, \mathrm{MD}$; Yousef Khader ${ }^{2}, \mathrm{PhD}$, Prof Dr \\ ${ }^{1}$ Ministry of Health, Amman, Jordan \\ ${ }^{2}$ Jordan University of Science and Technology, Irbid, Jordan
}

\section{Corresponding Author:}

Bayan Sarsour, MD

Ministry of Health

Ministry of Health building, 6th floor

Amman

Jordan

Phone: 96265200230 ext 2640

Fax: 96265688373

Email: Bayan sarsour@yahoo.com

\section{Abstract}

Background: Refugee children have an increased risk of physical and psychological illness. Data on behavioral and emotional problems among Jordanian and Syrian refugee children in noncamp settings are scarce.

Objective: This study aimed to assess the behavioral and emotional problems among Syrian school children refugees living outside camps in Jordan and their Jordanian counterparts.

Methods: A cross-sectional study was conducted among Syrian and Jordanian school children, aged 12-17 years, studying in the same schools in 4 Jordanian cities with the highest density of Syrian refugees. A self-reported questionnaire was used to collect information about the sociodemographic characteristics of the children. The Strengths and Difficulties Questionnaire was used to measure behavioral and emotional problems among these children.

Results: This study included a total of 1878 Jordanian adolescents (45.6\% male and 54.4\% female) and 1773 Syrian refugee adolescents (43.9\% male and $56.1 \%$ female). The parents of the Syrian adolescents were significantly less educated and had significantly lower total family income than Jordanian parents. More than half of the Jordanian and Syrian adolescents had peer relation problems (53.6\% and 55.5\%, respectively), 36.9\% of Jordanian and $35.5 \%$ of Syrian adolescents had hyperactivity or inattention problems, $44.8 \%$ of Jordanian and $47.6 \%$ of Syrian adolescents had conduct problems, and $30.8 \%$ of Jordanian and $32.0 \%$ of Syrian adolescents had emotional symptoms. On the other hand, $43.0 \%$ of Jordanian and $42.5 \%$ of Syrian adolescents had prosocial behaviors. In the multivariate analysis, Jordanian and Syrian children differed significantly in emotional symptoms and peer relationship problems. Compared with Jordanian children, Syrian children were less likely to experience emotional problems (odds ratio $0.81 ; P=.04$ ) and peer relationship problems (odd ratio $0.80 ; P=.03$ ).

Conclusions: Emotional and behavioral problems are common among Syrian refugee schoolchildren as well as Jordanian school children. They are all in need of urgent psychosocial support.

(iproc 2022;8(1):e36365) doi: $10.2196 / 36365$

\section{KEYWORDS}

emotional problems; behavioral problems; schoolchildren; Syrian refugees; Jordanian 
Edited by G Eysenbach; this is a non-peer-reviewed article. Submitted 12.01.22; accepted 13.01.22; published 04.02.22.

Please cite as:

Sarsour B, Aqel Sr A, Khader Y

Behavioral and Emotional Problems Among Jordanian and Syrian Refugee Children in Noncamp Settings iproc 2022;8(1):e36365

URL: https://www.iproc.org/2022/1/e36365

doi: $\underline{10.2196 / 36365}$

PMID:

(OBayan Sarsour, Ashraf Aqel Sr, Yousef Khader. Originally published in Iproceedings (https://www.iproc.org), 04.02.2022. This is an open-access article distributed under the terms of the Creative Commons Attribution License (https://creativecommons.org/licenses/by/4.0/), which permits unrestricted use, distribution, and reproduction in any medium, provided the original work, first published in Iproceedings, is properly cited. The complete bibliographic information, a link to the original publication on https://www.iproc.org/, as well as this copyright and license information must be included. 